\title{
Two new species of genus Rhopalopsole (Insecta, Plecoptera, Leuctridae) from China
}

\author{
Qian Yu-Han ${ }^{\dagger}, \mathrm{Du} Y u-Z h o u^{\ddagger}$ \\ Institute of Applied Entomology, Yangzhou University, Yangzhou, Jiangsu 225009, China \\ † urn:lsid:zoobank.org:author:E9541A64-EC44-4856-B2AB-B4E8400358F8 \\ $\ddagger$ urn:lsid:zoobank.org:author:1FDB5781-C8A0-4088-8D18-DCD5BB01C548 \\ Corresponding author: Du Yu-Zhou (yzdu@yzu.edu.cn)
}

Academic editor: C Geraci | Received 10 November 2011 | Accepted 29 November 2011 | Published 12 December 2011

urn:lsid:zoobank.org:pub:4FF53097-6BE4-4AB3-92FE-8462E8B2F56D

Citation: Yu-Han Q, Yu-Zhou D (2011) Two new species of genus Rhopalopsole (Insecta, Plecoptera, Leuctridae) from China. ZooKeys 154: 1-7. doi: 10.3897/zookeys.154.2234

\begin{abstract}
Two new species of Rhopalopsole Klapálek from China are described: R. exiguspina Du \& Qian, sp. n. and $R$. ampulla Du \& Qian, sp. n., which were collected in Guizhou province, China.
\end{abstract}

\section{Keywords}

Rhopalopsole, Leuctridae, Plecoptera, new species, China

\section{Introduction}

The genus Rhopalopsole belongs to the family Leuctridae and is distributed throughout the Oriental and Palaearctic Regions. The abdominal segments of Rhopalopsole species are unmodified, but the last segment bears on both lateral sides a chitinous process, the shape of which is an important character for distinguishing species. Cerci are onesegmented and slightly modified in males, and cerci shape varies according to species (Kawai 1967). The genus Rhopalopsole first was described by Klapálek from a Taiwanese species, $R$. dentata Klapálek (1912). Contributions to and revisions of Rhopalopsole were made by Okamoto (1922), Wu (1949, 1973), Illies (1966), Kawai (1967, 1968, 1969), Jewett (1958, 1975a, b), Harper (1977), Zwick (1977), Yang and Yang (1991a, 
b1994, 1995a, b), Yang et al. (2004) and Yang and Li (2006). Harrison and Stark (2008) provided a checklist of the genus that included 29 species, and an additional 43 species were subsequently described by Sivec et al. (2008), Stark and Sivec (2008), Yang et al. (2009), Li and Yang (2010), Li et al. (2010, 2011).

Here we describe two new Rhopalopsole species collected in Guizhou province, China. All type specimens were preserved in 75\% ethanol and deposited in the Insect Collection of Yangzhou University, Jiangsu, China.

\section{Taxonomy}

\section{Rhopalopsole exiguspina Du \& Qian, sp. n.} urn:lsid:zoobank.org:act:B26AB2A6-972F-4A18-9D1D-486A980CF80F http://species-id.net/wiki/Rhopalopsole_exiguspina Figs $1-4$

Material examined. Holotype $\widehat{\partial}$ from China, Guizhou, Yanhe County, Shaba Village,

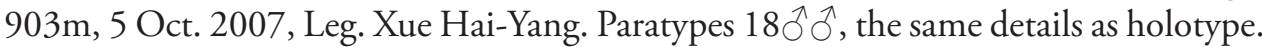

Adult habitus. General color: Light brown. Head brown or light brown, wider than prothorax, hind ocelli much closer to the eyes than to each other, antennae and palpi yellowish brown. Prothorax light brown, subquadrate, all angles somewhat rounded and some black irregular stripes on it. Legs light brown. Wings hyaline and veins light brown.

Male. Approximate measurement: forewing length $6.0 \mathrm{~mm}$, body length 6.5 mm. Mid-posterior margins of tergite 9 sclerotized, slightly emarginated (Fig. 1). Sternite 9 basally with a tongue-like vesicle bears dense hairs, apically with a subgenital plate wider than long and rounded apically (Fig. 2). Tergite 10 with strongly sclerotized lateral process beak-like somewhat acute and curving inward apically and a small spine at the middle of lateral process in dorsal view, thick basally and slightly curved upward apically in lateral view. Mid-anterior sclerite sclerotized, posterior margin more sclerotized; one pair of transverse triangle sclerite weakly sclerotized (Fig. 1). Epiproct a simple curved process, erect hook-like apical portion curved inward (Fig. 4). Subanal lobe sinuate in lateral aspect, rounded and strongly sclerotized apically, apex membranous in ventral aspect; subanal lobe clearly with a pair of little lobes at middle of subanal lobe and each little lobes rounded apically in ventral aspect. Cerci long and cylindrical, thick basally and thin apically, distinctly upturned in lateral aspect, apex with a tiny spine.

Female. Unknown.

Etymology. The species name refers to the small spine at the middle of lateral process of tergite 10 .

Diagnosis. This new species resembles Rhopalopsole aculeata Harper (1977) from Nepal and $R$. xui Yang, Zhu \& Li (2004) from Guangdong in having an epiproct with a thin spine-like apical portion and a strongly sclerotized lateral process without 


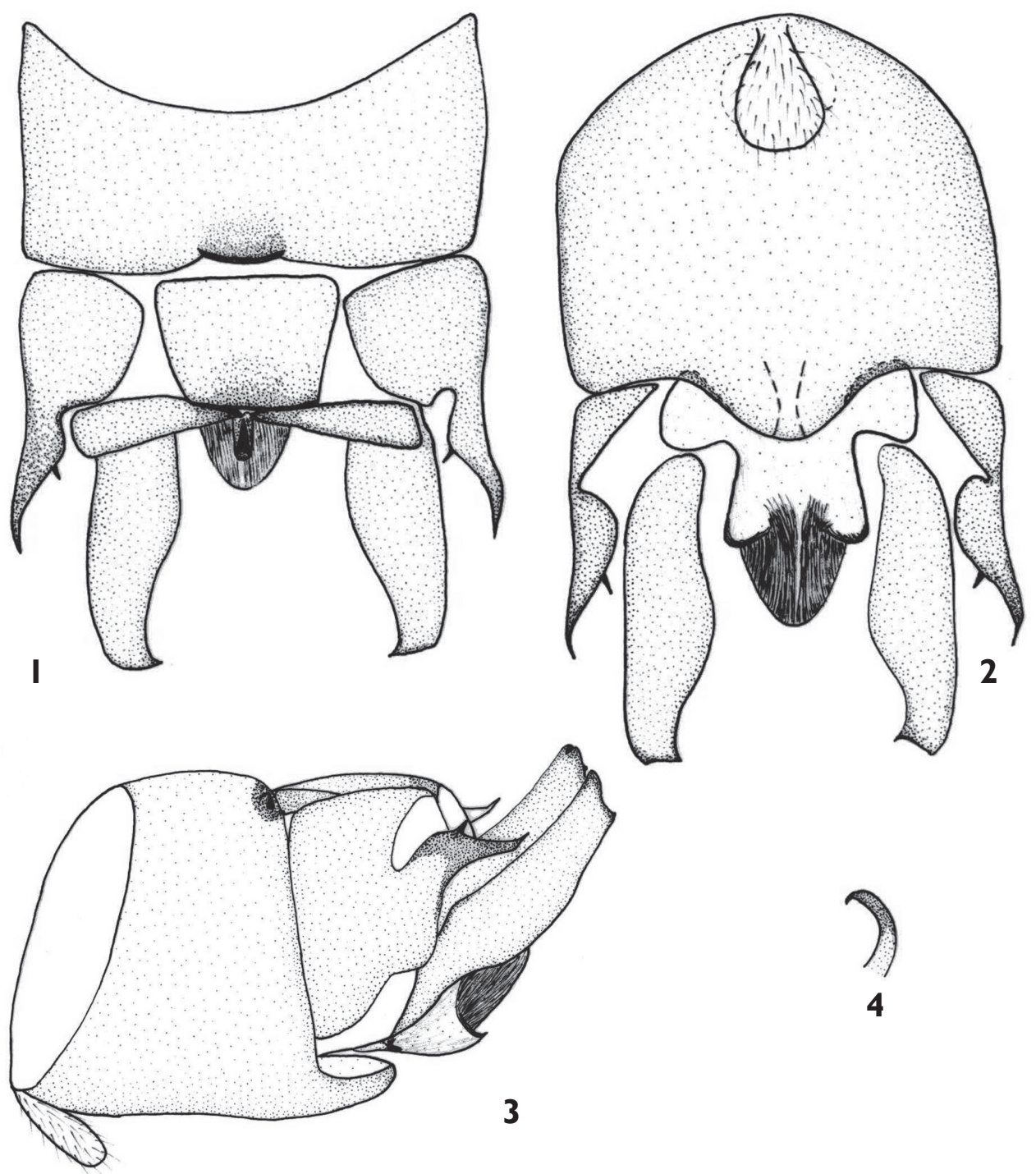

Figures I-4. Rhopalopsole exiguspina male structures I Male terminal, dorsal aspect 2 Male terminal, ventral aspect 3 Male terminal, lateral aspect 4 Epiproct, lateral aspect.

bifurcation of tergite 10 . The new species can be distinguished from $R$. aculeata by the presence of spines on the lateral processes and cerci. $R$. aculeate has no spines on the middle of lateral process or on the cerci. The new species can be distinguished from $R$. $x u i$ by the shapes of the mid-anterior sclerite, lateral process, subanal lobe and cerci. In $R$. xui, the mid-anterior sclerite is wider than long and has two short obtuse lateral processes. $R$. xui lacks spines at the middle of the lateral processes and on the cerci and has a wide and apically rounded subanal lobe without a pair of small lobes. The characteristics of the subanal lobe and lateral process distinguish this new species from other 
Rhopalopsole species, which possess an epiproct with thin spine-like apical portions and no bifurcated lateral processes on tergite 10 .

\section{Rhopalopsole ampulla Du \& Qian, sp. n.}

urn:Isid:zoobank.org:act:B6B94919-A1E4-48D2-9CE6-6AA7A1DF63C9

http://species-id.net/wiki/Rhopalopsole_ampulla

Figs 5-7

Material examined. Holotype $\delta$ from China, Guizhou, Yanhe County, Shaba Village, 903m, 5 Oct. 2007, Leg. Xue Hai-Yang. Paratypes $6 \hat{\jmath}$, the same details as holotype.

Adult habitus. General color: Brown and dark brown. Head brown or dark brown, wider than prothorax, hind ocelli much closer to the eyes than to each other, antennae and palpi brown. Prothorax dark brown, quadrate, longer than wide, all angles rounded and some black irregular stripes on it. Legs light brown. Wings hyaline and veins light brown.

Male. Approximate measurement: forewing length $8 \mathrm{~mm}$, body length $8.5 \mathrm{~mm}$. Tergite 9 sclerotized, with a large central membranous area, the mid-posterior margin strongly sclerotized (Fig. 5). Sternite 9 with a subgenital plate wider than long and rounded apically, basally with a tongue-like vesicle bears dense hairs (Fig. 6). Tergite 10 with two small narrow lateral mid-anterior sclerites and one large broad median mid-anterior sclerite; mid-posterior more sclerotized and protrusive; one pair of transverse sclerite weakly sclerotized (Fig. 5). Lateral processes each strongly sclerotized, spine-like rather than thick basally, narrowed apically and downward in lateral aspect (Fig. 7). Epiproct curved forward, thick and blunt apically (Fig. 5, 7). Subanal lobe strongly sclerotized at base, trident-like apically in ventral aspect and membranous at its apex (Fig. 6). Cerci long and cylindrical, ampulla-like, thick basally and thin apically, each with a tiny spine.

Female. Unknown.

Etymology. The species name refers to the shape of cerci on segment 10 .

Diagnosis. This new species is similar to other species in the Rhopalopsole assamensis group (Sivec et al. 2008) in having a sclerotized area on the mid-posterior margin of tergite 9, thick epiproct, lateral sclerites at each side of the central sclerite and cerci with tiny spines. It can be diagnosed by the shape of the subanal lobes, which are trident-like apically. Other species in the $R$. assamensis group possess subanal lobes that are flat and narrow at the base but expand into a wide rectangular apical portion. The lateral processes of species in the $R$. assamensis group typically end in a forked process on tergite 10 , but those of this new species lack bifurcation. $R$. ampulla is similar to $R$. exiguspina, but $R$. ampulla can be distinguished by the shapes of the subanal lobes and the lateral processes on tergite 10 . The subanal lobes of $R$. exiguspina are rounded apically and each posses a small spine at the middle of 

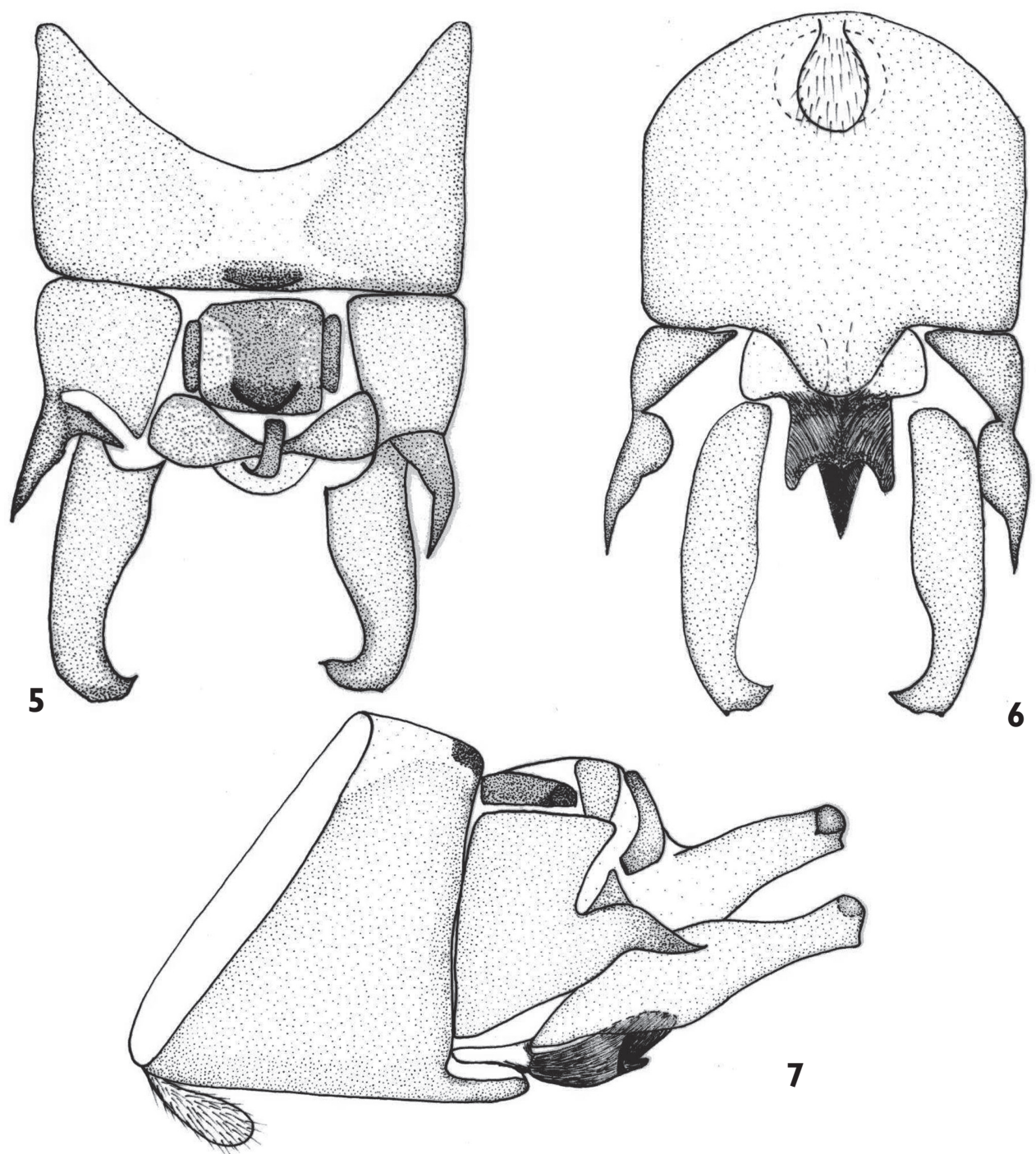

Figures 5-7. Rhopalopsole ampulla male structures 5 Male terminal, dorsal aspect 6 Male terminal, ventral aspect $\mathbf{7}$ Male terminal, lateral aspect.

lateral process, but those of $R$. ampulla are strongly sclerotized and trident-like apically in ventral aspect.

\section{Acknowledgments}

This research was supported by National Natural Science Foundation of China (No. 31071958). 


\section{References}

Harper PP (1977) Capniidae, Leuctridae and Perlidae (Plecoptera) from Nepal. Oriental Insects 11: 53-62.

Harrison AB, Stark BP (2008) Rhopalopsole alobata (Plecoptera: Leuctridae), a new stonefly species from Vietnam. Illiesia 4: 76-80.

Illies J (1966) Katalog der rezenten Plecoptera. In: Das Tierreich, Walter de Gruyter and Company Press, Berlin, 116-119.

Jewett SG (1958) Entomological survey of the Himalaya. Part XXIII - Stoneflies (Plecoptera) from the north-west (Punjab) Himalaya. Proceedings of the National Academy Sciences (India) 28: 320-329.

Jewett SG (1975a) Records of descriptions of Stoneflies from Northwest (Punjab) Himalaya and Mt. Malaku, Nepal Himalaya. Oriental Insects 9: 1-7.

Jewett SG (1975b) Some stoneflies from Bangladesh, India and Southeast Asia. Oriental Insects 9: $127-134$.

Kawai T (1967) Plecoptera (Insecta). In: Fauna Japonica, Electrical Engineering College Press, Tokyo. 42-48.

Kawai T (1968) Stoneflies from Thailand and India with descriptions of a new genus and two new species. Oriental Insects 2: 107-139.

Kawai T (1969) Stoneflies (Plecoptera) from Southeast Asia. Pacific Insects 11: 613-625.

Klapálek F (1912) Plecoptera I. In: Sauter's Formosa-Ausbeute H (Ed) Entomologische Mitteilungen 1, 342-351.

Li W-H, Kong F-B, Yang D (2011) A New Species of Rhopalopsole shaanxiensis species group (Plecoptera, Leuctridae) from China. Acta Zootaxonomica Sinica 36: 246-248.

Li W-H, Li G-L, Yang D (2010) A New Species of the Genus Rhopalopsole (Plecoptera: Leuctridae) from Sichuan, China. Acta Zootaxonomica Sinica 35: 310-312.

Li W-H, Yang D (2010) Two new species of Rhopalopsole vietnamica group (Plecoptera: Leuctridae: Rhopalopsole) from China. Zootaxa 2614: 59-64.

Okamoto H (1922) Zweiter Beitrag zar Kenntnis der Japanischen Plecopteren. Bulletin of the Agricultural Experiment Station, Government-General of Chosen, Korea 1: 1-46.

Sivec I, Harper P P, Shimizu T (2008) Contribution to the study of the oriental genus Rhopalopsole (Plecoptera: Leuctridae). Scopolia 64: 1-122.

Stark BP, Sicec I (2008) Rhopalopsole mataikan (Plecoptera: Leuctridae), a new stonefly species from Brunei Darussalam. Illiesia 4: 139-142.

Wu CF (1949) Third-sixth supplements to the stoneflies of China (Order Plecoptera). Peking Natural Histrory Bulletin 17: 251-256.

Wu CF (1973) New species of Chinese Stoneflies (Order Plecoptera). Acta Entomology Sinica 16: $97-118$.

Yang D, Li W-H, Zhu F (2004) Two new species of Rhopalopsole (Plecoptera: Leuctridae) from China. Entomological News 115: 279-282.

Yang D, Li W-H, Zhu F (2006) A new species of Rhopalopsole (Plecoptera: Leuctridae) from China. Entomological News 117: 433-435. doi: 10.3157/0013-872X(2006)117[433:AN SORP]2.0.CO;2 
Yang D, Shi L, Li W-H (2009) A new species of Rhopalopsole from oriental China (Plecoptera: Leuctridae). Transactions of the American Entomological Society 135: 193-195. doi: 10.3157/061.135.0207

Yang D, Yang C-K (1991a) New species of Plecoptera from Hubei. Journal of Hubei University 13: 369-372.

Yang D, Yang C-K (1991b) One new species of Rhopalopsole from Zhejiang. Journal of Zhejiang Forestry College 8: 78-79.

Yang D, Yang C-K (1994) Two new species of Rhopalopsole (Plecoptera: Leuctridae) from Shaanxi. Entomotaxonomia 16: 189-191.

Yang D, Yang C-K (1995a) Plecoptera: Leuctridae. In: Insects and Macrofungi of Gutianshan, Zhejiang, Zhejiang Science and Technology Press, Hangzhou, 20-24.

Yang D, Yang C-K (1995b) Plecoptera: Leuctridae. In: Insects of Baishanzu Mountain, Eastern China, China Forestry Publishing House Press, Beijing, 61-62.

Zwick P (1977) Ergebnisse der Bhutan - Expedition 1972 des Naturhistorischen Museums in Basel. Plecoptera. Entomologica Basiliensia 2: 85-134. 